\title{
Extracorporeal Perfusion for the Treatment of Acute Liver Failure
}

\author{
Henricus B.A.C. Stockmann, MD, Coen A. Hiemstra, MD, Richard L. Marquet, PhD, and Johannes N.M. IJzermans, MD, PhD
}

From the Department of Surgery, University Hospital Dijkzigt and Erasmus University, Rotterdam, The Netherlands

\section{Objective and Summary Background Data}

Because of the shortage of available donor organs, death rates from liver failure remain high. Therefore, several temporary liver-assisting therapies have been developed. This article reviews various approaches to temporary liver support as well as immunologic and metabolic developments toward a solution for this problem.

\section{Methods}

A literature review was performed using Medline and additional library searches to obtain further references. Only articles with a well-defined aim of study and methodology and a clear description of the outcome of the experiments were included.

\section{Conclusions}

Renewed interest has developed in old and new methods for an extracorporeal approach to the treatment of acute liver failure. Although temporary clinical improvement has been established, further research is needed to achieve a successful long-term clinical outcome. New developments in the field of genetic modification and tissue engineering await clinical application in the near future.
Because of the life-threatening complications of acute liver failure (ALF), $75 \%$ of patients die within a few days of onset. At present there is no satisfactory treatment for ALF except liver transplantation. Although liver transplantation is successful, with 5-year survival rates ranging from $70 \%$ to $80 \%$, there is a shortage of available donor organs. It is estimated that in the United States only $20 \%$ of the patients with ALF receive a transplant; $80 \%$ die while on the waiting list. ${ }^{1}$ The clinical need for an alternative is twofold: first, to bridge the gap until liver transplantation in case of irreversible damage, and second, to gain time for regeneration of the damaged liver.

Various liver-assisting therapies have been introduced since the early 1960s, including plasmapheresis, hemodilution, and cross-circulation, but none of them led to a significant clinical improvement. At the same time, extracorporeal whole liver perfusion was developed, with promising results. This method was abandoned in the early 1970s, however, because of the successful development of orthotopic liver transplantation and awareness of the possible immunologic implications. At present, the consensus is that

Correspondence: Johannes N.M. IJzermans, MD, Dept. of General Surgery, University Hospital Dijkzigt, P.O. Box 2040, 3000 CA Rotterdam, The Netherlands.

E-mail: ijzermans@hlkd.azr.nl

Accepted for publication November 4, 1999. the multiple and complex functions of the liver can be replaced only by using the biologic substrate (i.e., hepatocytes), whether in a whole liver or in combination with artificial material. This has led to increasing interest in the development of a bioartificial liver along with extracorporeal liver perfusion.

In addition to the worldwide shortage of available donor organs, new developments have made it worthwhile to pursue these solutions to the problem of ALF. The disadvantages and long-term effects of liver transplantation have become clear: a major and costly surgical procedure and lifelong immunosuppressive therapy. Further, the possibility of genetically modifying donor animals creates a unique opportunity to overcome potential immunologic barriers between species. In this review, we will assess the various approaches to a temporary solution for ALF; their shortcomings will be discussed and directions for future research suggested.

\section{EARLY LIVER-SUPPORT THERAPIES}

Acute or fulminant hepatic failure, usually induced by chemical or viral hepatitis, is highly lethal, with a death rate of more than $75 \%$ as a result of life-threatening complications such as portal hypertension, variceal bleeding, ascites, and hepatic encephalopathy. While the patient is waiting for possible liver transplantation, current treatment consists of 
Table 1. PATIENTS TREATED WITH EARLY LIVER-SUPPORT THERAPIES

\begin{tabular}{|c|c|c|c|c|c|}
\hline \multirow[b]{2}{*}{ Support System } & \multirow[b]{2}{*}{ No. of Patients } & \multicolumn{3}{|c|}{ Neurologic Improvement } & \multirow[b]{2}{*}{ Survival } \\
\hline & & Yes & No & Unknown & \\
\hline Hemodialysis ${ }^{4,5}$ & 65 & 33 & 17 & 15 & 17 (26\%) \\
\hline Hemofiltration ${ }^{6,7}$ & 15 & 10 & 5 & 0 & $8(53 \%)$ \\
\hline Exchange transfusion ${ }^{8-12}$ & 48 & 24 & 16 & 8 & $9(19 \%)$ \\
\hline Plasma exchange $\mathrm{e}^{13-15}$ & 32 & 15 & 17 & 0 & $7(22 \%)$ \\
\hline Resin hemoperfusion ${ }^{17,18}$ & 9 & 5 & 4 & 0 & $0(0 \%)$ \\
\hline Charcoal perfusion $20-23$ & 278 & 73 & 101 & 104 & $116(42 \%)$ \\
\hline
\end{tabular}

intensive clinical support: fluid and hemodynamic support, correction of electrolyte and acid-base abnormalities, respiratory assistance, and treatment of cerebral edema. In the past, it was thought that encephalopathy and cerebral edema were caused mainly by dialyzable toxins such as ammonia, false neurotransmitters, phenols, aromatic amino acids, and other substances with a molecular weight of less than $5,000^{2}$; early liver-support systems focused on blood detoxification. A kidney dialysis machine was used to remove blood ammonia, but this did not result in clinical improvement. $^{3}$ Because most of these toxins were thought to be protein-bound and traditional hemodialysis used cellulose membranes impervious to large molecules, polyacrylonitrile membranes were introduced that allowed passage of molecules up to a molecular weight of $15 \mathrm{kDa}$. Table 1 summarizes the results of the early liver-support therapies introduced in the 1950s and 1960s. In two groups treated with hemodialysis, ${ }^{4,5}$ temporary improvement in mental status and duration of survival occurred in more than half of the patients, suggesting at least partially effective removal of neurotoxins.

Hemofiltration has seen only limited application because of its major complication of thrombocytopenia, leading to bleeding in patients with an already compromised clotting system. ${ }^{6,7}$ Exchange transfusion showed initial improvement in neurologic status in several trials, but no effect on the death rate was found. ${ }^{8-12}$ With the less laborious technique of plasma exchange or plasmapheresis, ${ }^{13-15}$ significant improvements in neurologic status and biochemical profiles and decreased bleeding episodes were demonstrated; control of the hemorrhagic diathesis was achieved through the addition of coagulation factors. With this method, a better overall survival rate was achieved (34\% vs. $14 \%$ in the nontreated group); however, this was a nonrandomized study, and the groups were not controlled for cause or severity of the underlying disease. ${ }^{16}$

In hemoperfusion or plasma perfusion, the blood or plasma of a patient with ALF is perfused through a column containing activated charcoal or anion exchange resins. The latter caused no significant improvement, mainly because of early saturation of the resins and nonselective binding of the cations removed. ${ }^{17,18}$ After resolving the problems of platelet loss and hypotensive reactions by coating the columns and administering prostacyclin as a protective agent for the platelets, ${ }^{2,19}$ charcoal hemoperfusion yielded encouraging survival rates among patients with ALF. ${ }^{20-23}$ However, none of these studies included a proper control group defined by both the cause of the hepatic failure and the stage of disease. Thus, the effect of coated charcoal perfusion cannot be estimated conclusively. This technique is still in use because of the possible beneficial effect in combination therapies, where it is supposed to protect the adjacent liversupport therapy from toxic substances.

The detoxifying function of the above-mentioned techniques may in itself not be enough to improve the survival of patients with ALF. It remains to be determined whether these techniques, in combination with other liver-support therapies, will play a role in the future.

\section{BIOARTIFICIAL LIVER}

The limited success of detoxifying liver-support therapies and improved techniques for culturing isolated hepatocytes that express high levels of differentiated liver function in vitro have led to the development of the hybrid or bioartificial liver (BAL). These systems consist of biologic components (freshly isolated pig hepatocytes or human hepatoblastoma cell lines) in a synthetic framework. Isolated hepatocytes have been used in two ways, extracorporeal hepatocyte bioreactors and implantable hepatocyte systems; the latter is beyond the scope of this paper. In the extracorporeal bioreactors, the blood or plasma of the patient with ALF comes in contact with the cultured hepatocytes through an ex vivo perfusion system, as in the hemodialysis system for patients with renal insufficiency.

To create an artificial system containing viable hepatocytes, the procedure of culturing hepatocytes while maintaining their liver-specific function had to be improved. Culturing hepatocytes in suspension or in plastic tissue culture dishes causes the cells to lose their function within 24 hours and leads to cell death within days. ${ }^{24,25}$ Two solutions to this problem are being investigated: the use of transformed cells or cell lines, and optimization of the culture system for primary isolated hepatocytes. Another problem is how to expand the cell cultures to obtain sufficient quantities of hepatocytes in a relatively small volume 
Table 2. PATIENTS TREATED WITH ARTIFICIAL LIVER DEVICES

\begin{tabular}{|c|c|c|c|c|c|c|}
\hline \multirow[b]{2}{*}{ Support System } & \multirow[b]{2}{*}{ No. of Patients } & \multicolumn{3}{|c|}{ Neurologic Improvement } & \multirow[b]{2}{*}{ Survival } & \multirow[b]{2}{*}{ OLT } \\
\hline & & Yes & No & Unknown & & \\
\hline Suspension culture 27,28 & 60 & 60 & 0 & & $38(63 \%)$ & 0 \\
\hline Extracorporeal liver-assist device ${ }^{45,46}$ & 23 & 18 & & 5 & $14(61 \%)$ & 3 \\
\hline Bioartificial liver ${ }^{52}$ & 31 & 30 & & 1 & $22(71 \%)$ & 21 \\
\hline
\end{tabular}

to replace completely the function of a human liver. ${ }^{26}$ During the past 10 years, the development of clinically applicable BAL systems has focused on the volume of hepatocytes necessary to replace temporarily the liver function of the patient with ALF.

\section{Hepatocytes in Suspension Cultures or Encapsulated in Hydrogels}

Hepatocytes were first used in a liver support system in a clinical setting in 1987 by Matsamura et al (Table 2). ${ }^{27}$ Hepatocytes in a suspension culture were separated from the patient's blood by a cellulose acetate dialysis membrane. In this single patient, some clinical improvement was found. Because in vitro studies showed that hepatocytes function better when attached to a substrate, another attempt to establish a suspension system was made by Margulis et al, ${ }^{28}$ who seeded liver cells on Biosilon microcarriers. They demonstrated improved survival rates in the treated group $(63 \%)$ versus the group that received standard medical treatment $(41 \%)$. However, randomization for the stage of liver disease was not performed in the different groups, and no follow-up cases have been reported. Further in vitro studies demonstrated poorly preserved hepatocyte function after several hours of application. ${ }^{28,29}$

A rotating-disk type of artificial liver system, with hepatocytes trapped in a calcium alginate hydrogel, showed ammonia metabolism and urea synthesis in in vitro studies and subsequently significant removal of ammonia in an ex vivo animal study. ${ }^{30}$ Drawbacks of this system are the tendency of the gel phase to dissolve during hemoperfusion, with consequent loss of viability of the entrapped hepatocytes. This is why it was never applied in a clinical setting.

\section{Multiplated Hepatocyte Monolayers}

The system, which best resembles an in vitro culture of hepatocytes, was designed by Uchino et al in $1988 .{ }^{31}$ Hepatocytes were isolated from a canine liver and cultured on collagen-coated borosilicated glass plates in a monolayer. Stacking 200 plates in a transparent acryl resin module yielded about $80 \mathrm{~g}$ of hepatocytes, or one third of a canine liver, with stable function of the hepatocytes for 14 days. When this device was used to treat anhepatic dogs, clear- ance of ammonia was demonstrated in the treated group (vs. the groups receiving no treatment or plasma perfusion) and led to a significant increase in overall survival (55 vs. 24 hours). The same system has been used in in vitro studies of pig hepatocytes, which were perfused with plasma from patients with hepatic failure, ${ }^{32}$ and in the testing of in vitro hepatocyte culture techniques such as coculture and collagen-sandwich culture. ${ }^{33,34}$ These studies yielded the same encouraging results in vitro, but thus far no report of a clinical application has been published.

\section{Hollow Fiber Systems}

Most devices used to create a BAL consist of a bundle of small-diameter tubes, made of compatible cellulose acetate, enclosed in a rigid polycarbonate module (Fig. 1). This hollow fiber system has two compartments (intraluminal within the fibers and extraluminal outside the fibers) within the rigid housing; they communicate through the pores in the fiber walls. Because most of the waste molecules and bilirubin are bound to albumin (molecular weight 65-70 $\mathrm{kDa}$ ), the pore size chosen is usually a nominal molecular weight cutoff of $100 \mathrm{kDa}$; this excludes most complement factors and immunoglobins. ${ }^{35}$

\section{Intraluminal Gel Entrapment of Porcine Hepatocytes}

Prolonged viability and functioning of the hepatocytes are difficult to maintain at a high seeding density in an artificial liver. The viability and liver-specific functioning of hepatocytes are maintained by meeting several conditions, such as culturing on specific extracellular matrices, ${ }^{36,37}$ using a hormone-enriched culture medium, ${ }^{38,39}$ and ensuring three-dimensional orientation of the cultured hepatocytes. ${ }^{37} \mathrm{Gel}$ entrapment of hepatocytes allows most of the above. In these bioreactors, the primary isolated hepatocytes are inoculated into a collagen suspension in the intraluminal fiber space. The solution rapidly gels, resulting in hepatocytes entrapped in a three-dimensional matrix in the hollow fibers. The hepatocyte/collagen gel subsequently contracts to less than $50 \%$ of the original cross-section, resulting in three compartments: the contracted gel containing the hepatocytes, the rest of the intraluminal hollow fiber space, and 
Figure 1. Liver support device. After plasmapheresis, plasma circulates through a hollow fiber system in which isolated pig hepatocytes are cultured in the extracapillary space.

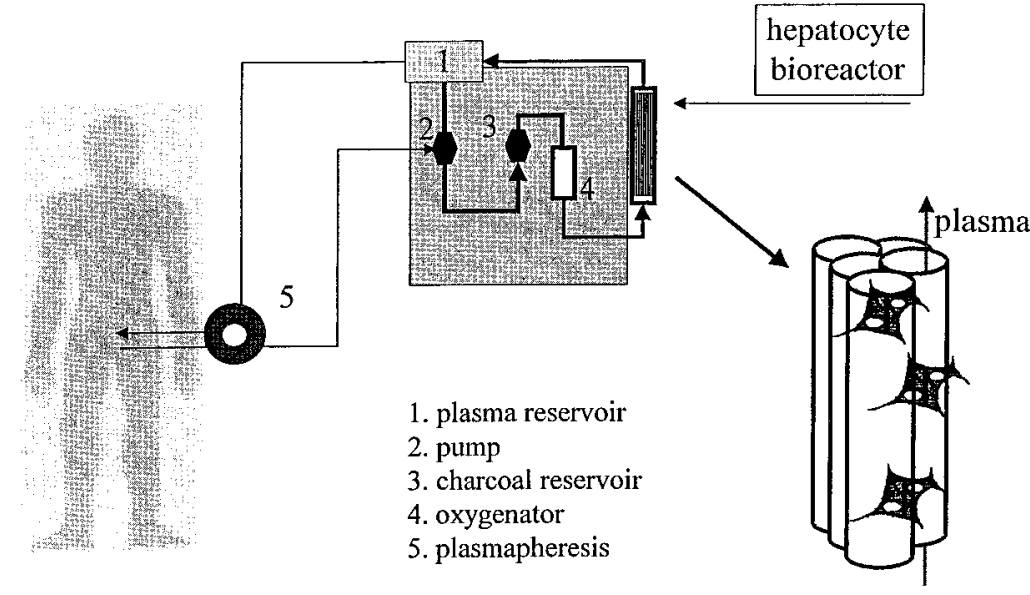

hollow fibers the extraluminal space within the rigid housing. Hepatocyte culture medium is perfused through the intraluminal space to keep the hepatocytes viable and functional when another medium (in the future, the patient's blood) is perfused through the extraluminal space. Proper functioning of this bioreactor has been demonstrated for 5 consecutive days in vitro, as measured by albumin synthesis, ureagenesis, and oxygen consumption. ${ }^{40}$ In an animal model of hepatic failure in small dogs $(<30 \mathrm{~kg})$, improved hemodynamic stability, delayed or absent hepatic encephalopathy, and improved survival were shown. ${ }^{41}$ Unfortunately, this concept yields only 0.5 to $1.0 \mathrm{~g}$ cells per bioreactor, ${ }^{42}$ which is not enough to treat humans. Although further characterization studies are being performed, ${ }^{43}$ the distance required for nutrients and exchangeable medium of the intraluminal gel-entrapped hepatocytes is not known, whereas the whole process of exchanging nutrients and toxic substances is dependent on passive diffusion through this gel.

\section{Extracorporeal Liver-Assist Device}

The C3A cell line is a highly differentiated, stable, and viral-free human cell line that performs a range of metabolic functions comparable to those of the normal liver. It has been shown to maintain viability and function for 4 to 8 months when seeded in a hollow fiber cartridge at high seeding density. In this concept, approximately $10 \mathrm{~g} \mathrm{C} 3 \mathrm{~A}$ cells is injected into the extraluminal space; the cells grow to confluence in 3 to 4 weeks and do not outgrow their culture space. Maturity is determined by glucose use and albumin production. It is thought that approximately $200 \mathrm{~g}$ C3A cells $\left(2 \times 10^{11}\right.$ hepatocytes $)$ is seeded in the bioreactor at confluence. ${ }^{44}$ Animal studies of dogs with acetaminophen-induced hepatic failure showed a significant biochemical improvement and improved survival. However, although the fibers have a nominal molecular weight cutoff of $70 \mathrm{kDa}$, human proteins such as human transferrin (molecular weight $90 \mathrm{kDa}$ ) and $\alpha_{1}$-antitrypsin were detected in dog serum, suggesting the transfer of human cell line material to the (canine) patient. ${ }^{44}$ Initial experience was encouraging: 11 patients were treated with the extracorporeal device and no short-term safety problems were observed; 10 patients showed biochemical improvement and 6 patients survived (see Table 2). ${ }^{45}$ In a second study, a pilot controlled trial, Ellis et $\mathrm{al}^{46}$ reported good survival for the treated group (78\%), but surprisingly also for the group receiving conventional treatment $(75 \%)$. The authors attribute the outcome of this trial to their choice of a group of patients with ALF at an earlier stage of the clinical course, when accurate predictors of prognosis are lacking. Further clinical studies will have to be performed to be able to justify the use of this system for patients with liver failure. More importantly, the long-term effects of leakage of human cell line material into the circulation of future patients, as previously shown, ${ }^{47}$ need to be assessed before the safety of this system can be established conclusively.

\section{Bioartificial Liver}

Because hepatocytes are known to be anchorage-dependent for prolonged viability and functioning, and to increase the effective surface area for hepatocytes in the hollow fiber cartridge, Demetriou et $\mathrm{al}^{48}$ used collagen-coated microcarriers for their BAL. After isolation of primary pig hepatocytes, the cells are incubated overnight with collagen-coated dextran microcarriers for attachment, and the microcarrierattached hepatocytes are inoculated into the extraluminal compartment of the hollow fiber system. In vitro and in vivo studies showed hepatocyte viability and functioning on microcarriers by conjugation of bilirubin, uptake of ${ }^{99 \mathrm{~m}} \mathrm{Tc}-$ DESIDA, and synthesis of liver-specific proteins (e.g., albumin) after implantation in albumin-deficient rats for 6 days. Moreover, similar functioning was measured after 2 weeks of storage of the microcarrier-attached hepatocytes at $-80^{\circ} \mathrm{C}$, suggesting that this part of the bioreactor can be prepared in advance. In vitro mass transfer studies were performed to determine the optimal operating parameters for a hollow fiber cartridge serving as a BAL. These studies 
demonstrated that cells attached to the microcarriers do not bind to the fibers, thereby allowing free convection of plasma/perfusion medium with an optimal cross-fiber pressure drop at high-flow recirculation of plasma. ${ }^{49}$ Significant metabolic support was shown when cryopreserved microcarrier-attached pig hepatocytes were used in the BAL to treat dogs with acute liver failure continuously for 6 hours, introducing plasmapheresis to avoid hemolysis and platelet depletion in the perfusion system. The viability of the cells after 6 hours of both allogeneic and xenogeneic perfusion was $90 \%$. Unfortunately, survival was not one of the endpoints of this study ${ }^{50}$ A charcoal column was added to the extracorporeal perfusion system before perfusion through the BAL because it was assumed that this would protect the porcine hepatocytes from the toxic hepatic failure plasma. ${ }^{51}$ This system, including plasmapheresis, charcoal column, and cryopreserved primary isolated microcarrier-attached pig hepatocytes (approximately $4-6 \times 10^{9}$ ) inoculated into the extraluminal space of a hollow fiber cartridge, was used for the first time to treat a patient in 1993, leading to a phase I clinical trial with 31 patients (see Table 2). Eighteen patients with fulminant hepatic failure, 3 patients with primary nonfunction after liver transplantation, and 10 patients with acute exacerbation of chronic liver disease were treated successfully, as indicated by significant neurologic improvement, decreased intracranial pressure, decreased plasma ammonia levels, and improvement of other biochemical parameters. Liver transplantation followed in 21 of the 31 patients; the other 8 patients were not eligible for transplantation. ${ }^{52}$

Although this system gave promising results and a phase II/III clinical trial is being prepared to determine efficacy, further studies are needed to establish the immunologic consequences of perfusing human plasma through a device containing pig hepatocytes. In addition, the possible transfer of viral material from the bioreactor to the host must be monitored in detail.

Also, the long-term stable culture of human hepatocytes must be explored. Recent studies have shown normal proliferation of human blastocyst-derived, pluripotential embryonic stem cell lines, which differentiate into derivatives of all three embryonic germ layers. ${ }^{53}$ These cell lines could possibly be used to develop noncarcinogenic human hepatocytes. When incorporated into a BAL, this could result in a functional device without the immunologic drawbacks and the potential danger of a human hepatoblastoma cell line.

\section{EXTRACORPOREAL WHOLE LIVER PERFUSION}

The need for hepatic tissue for effective treatment of patients with ALF led to the concept of using the whole liver in an extracorporeal perfusion system. Isolated liver perfusion studies date back to the 19th century, when they were performed to study liver metabolism, demonstrating complex metabolic liver function outside the natural envi-

\section{Table 3. CLINICAL STUDIES USING EXTRACORPOREAL PIG LIVER PERFUSION}

\begin{tabular}{lcrr}
\hline Investigators & $\begin{array}{c}\text { Publication } \\
\text { Year }\end{array}$ & $\begin{array}{c}\text { No. of } \\
\text { Patients }\end{array}$ & $\begin{array}{c}\text { No. of } \\
\text { Perfusions }\end{array}$ \\
\hline Eiseman* & $1965 / 1966$ & 8 & 11 \\
Norman & 1967 & 5 & 13 \\
Watts* & 1967 & 3 & 6 \\
Bertrand & 1968 & 10 & 15 \\
Beveridge & 1968 & 1 & 1 \\
Mieny & 1968 & 1 & 1 \\
Ham & 1968 & 1 & 2 \\
Abouna* & $1968 / 1969$ & 4 & 7 \\
Watts & 1969 & 5 & 8 \\
Schleifer & 1969 & 2 & 2 \\
Häring & 1969 & 3 & 4 \\
Chevrel & $1969 / 1970$ & 4 & 4 \\
Abouna & 1970 & 1 & 10 \\
Ranek & 1971 & 5 & 7 \\
Parbhoo* & 1971 & 5 & 6 \\
Lempinen & 1971 & 1 & 3 \\
Nielubowicz & $1972 / 1973$ & 5 & 10 \\
Margulis & 1975 & 10 & 10 \\
Tung* & 1981 & 9 & 13 \\
Chari* & 1994 & 4 & 8 \\
& & 87 & 141
\end{tabular}

* Studies analyzed for Table 4.

ronment of the liver. ${ }^{54}$ Not until 1958 was the first experimental study carried out with allogeneic livers to clear ammonia given to dogs. The study showed a significant decrease in ammonia levels in animals treated by ex vivo liver perfusion compared with control animals. ${ }^{55}$ The first clinical study was performed in 1965 by Eiseman et al, ${ }^{56}$ who tested several perfusion circuits in pigs as well as humans with ALF. During the past three decades, approximately 141 ex vivo pig liver perfusions have been performed to treat 87 patients with liver failure in usually poor clinical condition (Table 3). The technique and clinical outcome of extracorporeal whole pig liver perfusion, as reported in well-documented studies comprising more than one patient, are described below.

\section{Experimental Setup}

The pig liver has been used in most cases because it is readily available. Immediately before perfusion, hepatectomy is performed on pigs weighing 20 to $45 \mathrm{~kg}$. In all studies, the cystic duct is ligated, the common bile duct is cannulated to collect the bile produced during perfusion, and the hepatic artery and the portal vein are cannulated for inflow of human blood. The inferior vena cava is either left open, in which case outflow goes to a reservoir where the patient's blood is mixed with ascitic fluid and pumped back into the circulation, or cannulated for immediate return of blood to the patient. The isolated liver is placed in a sterile 
Table 4. PATIENTS TREATED WITH EXTRACORPOREAL LIVER PERFUSION

\begin{tabular}{|c|c|c|c|c|c|c|}
\hline Cause & $\begin{array}{l}\text { No. of } \\
\text { Patients }\end{array}$ & $\begin{array}{c}\text { No. of } \\
\text { Perfusions }\end{array}$ & $\begin{array}{c}\text { Neurologic } \\
\text { Improvement/Perfusion }\end{array}$ & $\begin{array}{c}\mathrm{NH}_{3} \\
\text { Decrease } \\
(\%)\end{array}$ & $\begin{array}{c}\text { Bilirubin } \\
\text { Decrease } \\
(\%)\end{array}$ & Survival (Mean) \\
\hline Cirrhosis & 11 & 15 & $14 / 15$ & 55 & 36 & 4.8 days \\
\hline Viral hepatitis & 10 & 16 & $10 / 16$ & 43 & 41 & $\begin{array}{l}4.8 \text { days }+1 \text { complete } \\
\text { recovery }\end{array}$ \\
\hline $\begin{array}{l}\text { Liver failure not } \\
\text { otherwise specified }\end{array}$ & 12 & 19 & $16 / 19$ & 25 & 47 & $\begin{array}{l}4.3 \text { days }+2 \text { complete } \\
\text { recoveries }\end{array}$ \\
\hline
\end{tabular}

perfusion chamber and connected to the patient's circulatory system within no more than 30 minutes. Bile flow proved to be the single most reliable index of hepatic function and was assessed in all cases of extracorporeal liver perfusion.

Many perfusion configurations have been tested. ${ }^{56}$ In general, either blood is drawn from the femoral artery and returned to the patient through the saphenous vein, or a direct arteriovenous shunt in the upper arm is used. ${ }^{56-61}$ In other studies, a venovenous shunt was used, placing a double-lumen catheter in the femoral vein ${ }^{59}$ or using the femoral and jugular veins. ${ }^{62}$ As is known from isolated liver perfusion studies, oxygen supply to the liver is vital. Therefore, the addition of a heater-oxygenator unit to the perfusion system ensures a blood supply with a temperature of $37^{\circ}$ to $39^{\circ} \mathrm{C}$ and $100 \%$ oxygen saturation. Thus, there is no difference in performance of the ex vivo liver between perfusing the hepatic artery and the portal vein or the portal vein alone. ${ }^{56}$ A pump is used in the perfusion circuit, either to return the blood from the reservoir containing "post"-ex vivo liver blood to the patient ${ }^{56,58,60,61}$ or to create stable and constant pressure and flow into the liver when a venovenous bypass was used. ${ }^{59,62}$ Length of extracorporeal pig liver perfusion varied from 1.5 to 9 hours; one to four perfusions were performed per patient. Regional or systemic heparin was administered.

\section{Clinical Outcome}

For the literature review, references 56 to 62 were chosen because their documentation is the best and the techniques used for extracorporeal pig liver perfusion are comparable. The variation in the cause of the hepatic failure among individual patients from each study makes it hazardous to compare the success rate of the ex vivo liver perfusion technique. In addition, one is tempted to assume that some groups of patients (e.g., those with ALF compared with those with chronic liver disease) may exhibit a better outcome; therefore, we determined neurologic improvement, the percentage decrease in levels of $\mathrm{NH}_{3}$ or bilirubin before and after perfusion, as well as the mean survival (in days) to compare the results of patients with the same cause from the different groups. Five patients who received eight perfusions have been excluded because they had single-case diseases such as hepatic failure from septic shock, hemochromatosis, acetaminophen intoxication, and primary graft nonfunction. Of the remaining 33 patients, 11 had cirrhosis from alcohol abuse, 10 had viral hepatitis, and 12 had hepatic failure not otherwise specified (Table 4). All patients had coma hepaticum grade IV to V (Table 5), and all other treatments had failed to that point.

The results show neurologic improvement to at least coma hepaticum grade III to II in most patients, which does not seem to be related to the cause of the hepatic failure. Moreover, no relation between clearance of $\mathrm{NH}_{3}$ or bilirubin and neurologic improvement or survival and cause was demonstrated. This underlines the fact that the biochemical parameters used to describe the function of the isolated liver and to follow the clinical condition of patients with hepatic failure do not reveal the mechanism of hepatic failure and hepatic encephalopathy. Although controlled trials have not yet been carried out, the complete recovery of three patients and the prolonged survival of some patients strongly suggest improvement over conventional treatment.

Most complications that accompany extracorporeal

\section{Table 5. CLINICAL STAGES OF ACUTE FULMINANT HEPATIC FAILURE (HEPATIC COMA)}

\begin{tabular}{|c|c|c|}
\hline Grade & Description & Clinical Symptoms \\
\hline I & $\begin{array}{l}\text { Neurasthenic } \\
\text { syndrome }\end{array}$ & $\begin{array}{l}\text { Abnormal fatigability, depression, } \\
\text { confusion, altered mood or behavior, } \\
\text { appropriate response, slight tremor }\end{array}$ \\
\hline$\|$ & Somnolence & $\begin{array}{l}\text { Drowsiness, inappropriate behavior, } \\
\text { flapping tremor }\end{array}$ \\
\hline III & Sopor & $\begin{array}{l}\text { Reduced responsiveness, ability to obey } \\
\text { simple commands, incoherent speech, } \\
\text { Babinski }\end{array}$ \\
\hline IV & Coma & $\begin{array}{l}\text { No response to verbal stimuli, response } \\
\text { to painful stimuli, decerebrate, grossly } \\
\text { abnormal EEG }\end{array}$ \\
\hline V & Deep coma & $\begin{array}{l}\text { No response to pain, little or no EEG } \\
\text { activity }\end{array}$ \\
\hline
\end{tabular}


whole liver perfusion are due to preexisting cardiopulmonary disease, although hemodynamic changes during perfusion were highly limited. Uncontrolled bleeding secondary to thrombocytopenia as a result of the oxygenator in the circuit or the development of disseminated intravascular coagulation is another common complication. In three patients, a relapse to stage $\mathrm{V}$ hepatic encephalopathy eventually led to death.

Most ex vivo liver perfusion studies were performed in the late 1960s and early 1970s; the method was then abandoned because of the successful development of orthotopic liver transplantation (see Table 3). However, with the present shortage of available donor organs, there is renewed interest in this method. ${ }^{62-64}$ Although the results are encouraging, a controlled study has not yet been performed to predict conclusively the outcome of extracorporeal whole liver perfusion. Further, the immunologic implications of human blood perfused through hepatic endothelial tissue are unknown. This aspect will be considered in the next section.

\section{IMMUNOLOGIC IMPLICATIONS}

The use of extracorporeal pig liver perfusion or an artificial liver device with pig hepatocytes implies contact of human blood or plasma with porcine material. When such an xenogeneic contact is established, whether it be only once or several times per patient for limited periods of time, immunologic problems should be anticipated. In the first clinical study on extracorporeal liver perfusion by Eiseman et al in $1965,{ }^{56}$ $\mathrm{C}^{14}$-tagged glycine and lysine were added to the perfusion system and synthesized into protein by the pig liver that probably contained the porcine amino acid code, suggesting exchange of biologic material between graft and host. Renewed interest in the application of xenogeneic cells or tissues has drawn attention to the possible immunologic consequences. Although a cell-mediated reaction is seen at an early stage, as indicated by activation of neutrophil granulocytes and natural killer cells after suppression of complement, ${ }^{65,66}$ these mechanisms are probably less significant because therapy is intended to last only several days. For this reason, we will focus on the humoral response.

\section{Humoral Response}

Xenotransplantation normally leads to hyperacute rejection of the xenograft mediated by preformed naturally occurring antibody (pNAb) and complement. These antibodies, also called xenogeneic pNAbs, are directed against porcine antigens and are present in most primates without preceding sensitization. In humans, xenoreactive pNAbs, which consist of $\operatorname{IgG}, \operatorname{IgA}$, and mainly $\operatorname{IgM}$, form $2 \%$ to $4 \%$ of the total immunoglobulins. Approximately $80 \%$ of these pNAbs are directed against the GAL-alpha ${ }^{1,3}$ membrane epitope, the most important target antigen of the human humoral defense against porcine organs. ${ }^{66}$ pNAbs are mainly produced by splenic B lymphocytes,${ }^{67}$ and several theories about their development have emerged. For instance, they may be induced by contact between mucosal immune cells and intestinal flora ${ }^{68}$ or food-derived antigens with epitopes similar to GAL. ${ }^{69}$ Whether IgG, with a higher affinity for pig antigens, or IgM, which is supposed to act as an "early" antibody, plays the predominant role in complement activation and cytotoxicity has yet to be established. ${ }^{70}$ In a recent study by Schraa et al, ${ }^{71}$ rats were sensitized against hamsters 1 and 5 weeks before hepatic xenografting; high titers of IgM and IgG, respectively, were found. Hyperacute rejection was demonstrated in the second group but not the first group, indicating the importance of $\mathrm{IgG}$ but not IgM-mediated cytotoxicity in hepatic xenografting. As for the direct effect of complement, both the classical and the alternative pathways seem to be involved in the activation and cytotoxicity of a xenogeneic reaction. ${ }^{69}$

\section{Immunologic Aspects in Liver Perfusion}

In patients with ALF, the levels of total $\mathrm{CH} 50$ and $\mathrm{C} 3$, $\mathrm{C} 4, \mathrm{C} 5$ and the regulatory proteins factor I and beta- $1 \mathrm{H}$ are significantly lower compared with controls, ${ }^{72}$ whereas the naturally occurring antibody levels do not differ. It is not clear whether this complement depletion is the result of impaired synthesis because of the diseased liver or ongoing activation of the complement system, or a combination of the two. Hyperacute rejection after xenogeneic kidney perfusion can be prevented only by complete inactivation of complement, ${ }^{73}$ whereas the perfusion of a liver with human blood is characterized by normal liver function for several hours. ${ }^{74}$ At the same time, the drops in the levels of pNAbs during kidney and liver perfusion are similar. However, immunohistochemical analysis of the kidneys after perfusion with human blood demonstrates the binding of both IgM and IgG xenoantibodies and complement (C3) to kidney vascular endothelium, whereas staining was minimal for liver vascular endothelium. ${ }^{75}$

Tector et $\mathrm{al}^{76}$ confirmed these data in an isolated liver perfusion study of blood from patients with liver failure. They showed significantly reduced complement levels and activity compared with normal subjects, resulting in an impaired ability to lyse both aortic and sinusoidal endothelial cells. Immunofluorescent analysis showed little or no staining for sinusoidal deposition of $\operatorname{IgM}, \operatorname{IgG}$, or $\mathrm{C} 3$, suggesting that the sinusoidal endothelium of the liver can remove antibody and complement without cell lysis, possibly by endocytosis, compared with aortic or other endothelium.

The same results were obtained in a clinical study in which no adverse effects on ex vivo organ function were measured during treatment of patients with ALF by extracorporeal pig liver perfusion. Again, low complement levels, normal amounts of pNAb, and, after perfusion, only trace deposits of pNAb and $\mathrm{C} 3$ on the sinusoidal endothelium with a decrease in the level of pNAb were demonstrated. ${ }^{77}$ Long-term follow-up of these patients showed an 


\section{Table 6. STRATEGIES TO OVERCOME HYPERACUTE REJECTION OF PIG-TO- HUMAN XENOGRAFTS}
Antibody
- Removal by plasmapheresis, immunopheresis
- Removal by absorption with pig organs
- Removal by absorption on gal columns
- Block with high avidity chicken anti-GAL
- Block with peptides
Antigen
- Gene knockout (not in pig)
- Antisense constructs
- Enzymatic destruction:
External
Galactosidase transgene
- Suppress GAL:
$\mathrm{H}$ transferase transgene
- Secretor gene
Complement
- Cobra venom factor
- Antibodies
- Soluble complement receptor type 1
- Transgenes (CD46[MCP], CD55[DAF], CD59)

Adapted from McKenzie et al. ${ }^{79}$

increase in xenoreactive $\operatorname{IgM}$ and $\operatorname{IgG}$ within 10 days of perfusion and a subsequent return to normal. ${ }^{78}$ These concepts are being used to study ways to delay hyperacute rejection (Table 6) ${ }^{79}$ Several strategies are being tested in different organs, with encouraging results. The efficacy of humoral mediators present in serum has been reduced by means of porcine livers transgenic for human decay-accelerating factor (DAF/CD55). ${ }^{80}$ Reduced humoral injury was found with soluble complement receptor type $1,{ }^{81}$ and immunopheresis was successfully used to remove xenogeneic pNAb before perfusion of the liver, which resulted in improved functioning of the perfused liver. ${ }^{82}$

The role of the immunologic defense in the treatment of patients with liver failure is far from clear, but no immunologic adverse reactions have been detected during treatment in the clinical studies reported thus far. In one patient with chronic aggressive hepatitis who underwent 16 extracorporeal liver perfusions in 2.5 months, a decrease in antibodies could be shown after every perfusion. This was followed by a progressive rise in the titer of these antibodies, which peaked during the fifth perfusion, when an anaphylactic reaction was recorded; the next five perfusions with a pig liver did not cause detrimental effects. ${ }^{83}$ Whether prolonged or repetitive treatment leads to sensitization of the patient to porcine antigens remains to be determined.

\section{Immunologic Aspects of Artificial Liver Devices}

Unlike extracorporeal whole liver perfusion, where human blood is in direct contact with porcine liver endothe- lium, artificial liver systems contain only pig hepatocytes and are usually perfused with human plasma, because a plasma separation unit is used in the perfusion circuit. As described before, the hollow fiber bioreactor consists of several compartments that communicate through the pores in the fiber walls, allowing mass transfer between the patient's plasma and the heterologous hepatocytes. The size of the pores is determined by the balance between sufficient waste removal and potential immune activation. Removal of ammonia, aromatic amino acids, and red blood cell breakdown products such as bilirubin $(0.6 \mathrm{kDa})$ is desirable. Coagulation proteins such as prothrombin $(70 \mathrm{kDa})$ and thrombin $(40 \mathrm{kDa})$ could potentially benefit the patient, which is why they should be allowed to pass through the fiber membrane. However, immunoglobulins (150-900 $\mathrm{kDa})$ and cytokines $(100-400 \mathrm{kDa})$ preferably do not make contact with the hepatocytes. The ideal molecular weight cutoff therefore may lie between 50 and $100 \mathrm{kDa},{ }^{35}$ which should theoretically prevent a cellular as well as a humoral immune response.

However, te Velde et $\mathrm{al}^{84}$ showed that rats infused with the supernatant of in vitro cultured pig hepatocytes raised antibodies against the very small amounts of pig hepatocyte-derived proteins in the culture medium. Another study showed an increase in tumor necrosis factor-alpha after a 4-day perfusion of pigs connected to a hybrid liver support system containing homologous hepatocytes, ${ }^{85}$ although no typical side effects were observed. In a clinical study of patients with ALF treated with the BAL, antipig xenoantibodies (IgM and $\operatorname{IgG}$ ) remained at the same level 10 days after treatment, when one treatment was carried out. If more than one treatment was given, the levels increased two- to threefold and decreased only if immunosuppression was administered because of subsequent liver transplantation. ${ }^{86}$ Thus, either through contact of human plasma with the pig hepatocytes during perfusion or because of pig hepatocyte material entering the human circulation, an immunologic reaction can be induced. Whether this is clinically relevant remains to be seen, because so far no side effects have been noticed.

Cellular and humoral graft-versus-host reactions also must be considered, although thus far there is no proof of this type of reaction in the literature. In a baboon-to-human liver transplantation, no baboon antibodies were detected in the human serum. ${ }^{87}$ Another problem is the potential risk of zoonosis. Patience et $\mathrm{al}^{88}$ showed that porcine kidney cell lines release particles of pig endogenous retrovirus, which can infect human cell lines in vitro. However, transmission of pig endogenous retrovirus from transplanted porcine endothelial cells to baboons ${ }^{89}$ or humans ${ }^{90}$ in vivo has not been detected. Obviously, these issues need further attention if artificial liver systems are to be used in clinical trials.

\section{CONCLUSIONS}

Two major concerns are noted in the literature on extracorporeal liver perfusion for the treatment of liver failure. 
First, there is still no clear understanding of the biologic mechanisms of liver failure; therefore, the various approaches to temporary treatment of this disease lack a well-defined basis. Second, no uniform definition of liver failure is given. Within studies and between studies, there is a wide variety in the severity of liver disease, and success of treatment is defined in many ways. Although most studies report temporary improvement of the patient's clinical neurologic condition, evidence-based research indicating successful treatment has not yet been reported. Therefore, in our opinion, randomized studies that focus on a well-defined method and include sufficient patients to allow adequate statistical analysis are needed to determine the efficacy of this approach. Only then can conclusive evidence be gathered to benefit patients with liver failure who undergo either extracorporeal whole liver perfusion or treatment with a BAL.

\section{References}

1. Lee W. Acute liver failure. N Engl J Med 1994; 329:1862-1872.

2. Chang TMS. Haemoperfusions over a microencapsulated adsorbent in a patient with hepatic with hepatic coma. Lancet 1972; 2:1371-1372.

3. Kiley JE, Welch HF, Pender JC, Welch CS. Removal of blood ammonia by hemodialysis. Proc Soc Exp Biol Med 1956; 91:489-490.

4. Silk DB, Trewby PN, Chase RA, et al. Treatment of fulminant hepatic failure by polyacrylonitrile-membrane haemodialysis. Lancet 1977; 2:1-3.

5. Denis J, Opolon P, Nusinovici V, Granger A, Darnis F. Treatment of encephalopathy during fulminant hepatic failure by haemodialysis with high-permeability membrane. Gut 1978; 19:787-793.

6. Denis J, Opolon P, Delorme ML, Granger A, Darnis F. Long-term extracorporeal assistance by continuous haemofiltration during fulminant hepatic failure. Gastroenterol Clin Biol 1979; 3:337-348.

7. Rakela J, Kurtz SB, McCarthy JT, et al. Postdilution hemofiltration in the management of acute hepatic failure: a pilot study. Mayo Clin Proc 1988; 63:113-118.

8. Lee C, Tink A. Exchange transfusion in hepatic coma: report of a case. Med J Aust 1958; 1:40-42.

9. Trey C, Burns DG, Saunders SJ. Treatment of hepatic coma by exchange blood transfusion. N Engl J Med 1966; 274:473-481.

10. Ritt DJ, Whelan G, Werner DJ, Eigenbrodt EH, Schenker S, Combes B. Acute hepatic necrosis with stupor or coma. An analysis of 31 patients. Medicine 1969; 48:151-172.

11. Mckechnie JC, Hersh T. Exchange transfusion in hepatic coma. A review of 19 cases. Am J Gastroenterol 1971; 56:17-43.

12. Redeker AG, Yamahiro HS. Controlled trial of exchange-transfusion therapy in fulminant hepatitis. Lancet 1973; 1:3-6.

13. Lepore MJ, Stutman LJ, Bonanno CA, Conklin EF, Robilotti JG Jr, McKenna PJ. Plasmapheresis with plasma exchange in hepatic coma. II Fulminant viral hepatitis as a systemic disease. Arch Intern Med 1972; 129:900-907.

14. Haapanen E, Tiula E. Plasmapheresis with albumin as main substitute in acute hepatic coma. Scand J Gastroenterol 1972; 7:75-83.

15. Matsabura S, Okabe K, Ouchi K, et al. Continuous removal of middle molecules by hemofiltration in patients with acute liver failure. Crit Care Med 1990; 18:1331-1338.

16. Yamazaki Z, Kanai F, Idezuki Y, Inoue N. Extracorporeal methods of liver failure treatment. Biomater Artif Cells Artif Organs 1987; 15: 667-675.

17. Ching NP, Nealon TF Jr, Gibbon JH Jr. An extracorporeal device for hepatic coma. JAMA 1963; 183:350-354.
18. Juggi JS. Extracorporeal cation-exchange circuits in the treatment of hyperammonaemia of hepatic failure. Med J Aust 1973; 60:926-930.

19. Gimson AES, Mellon PJ, Braude S, Canalese J, Williams R. Earlier charcoal haemoperfusion in fulminant hepatic failure. Lancet 1980; 1:173-175.

20. Gazzard BG, Weston MJ, Murray-Lyon IM, et al. Charcoal haemoperfusion in the treatment of fulminant hepatic failure. Lancet 1974; 1:1301-1307.

21. Hughes R, Williams R. Clinical experience with charcoal and resin hemoperfusion. Semin Liver Dis 1986; 6:164-173.

22. Gimson AES, Mellon PJ, Braude S, Canalese J, Williams R. Earlier charcoal haemoperfusion in fulminant hepatic failure. Lancet 1982; 2:681-683.

23. O'Grady JG, Gimson AES, O'Brien CJ, Pucknell A, Hughes RD, Williams R. Controlled trials of charcoal haemoperfusion and prognostic factors in fulminant hepatic failure. Gastroenterology 1998; 94:1186-1192.

24. Sutherland DER, Numata M, Matas AJ, Simmons RL, Najarian JS. Hepatocellular transplantation in acute liver failure. Surgery 1977; 82:124-132.

25. Reid LM, Jefferson DM. Culturing hepatocytes and other differentiated cells. Hepatology 1984; 4:548-559.

26. Stockmann HBAC, Tompkins RG, Berthiaume F. Expression of longterm liver-specific function by adult rat hepatocytes cultured on microcarriers. Tissue Eng 1997; 3:267-279.

27. Matsamura KN, Guevera GR, Huston H, et al. Hybrid bioartificial liver in hepatic failure: preliminary clinical report. Surgery 1987; 101:99103.

28. Margulis MS, Erukhimov EA, Andreiman LA, Viksna LM. Temporary organ substitution by hemoperfusion through suspension of active donor hepatocytes in a total complex of intensive therapy in patients with acute hepatic insufficiency. Resuscitation 1989; 18:85-94.

29. Shnyra A, Bocharov A, Bochkova N, Spirov V. Bioartificial liver using hepatocytes on Biosilon microcarriers: treatment of chemically induced acute hepatic failure in rats. Artif Organs 1991; 15:189-197.

30. Yanagi K, Ookawa K, Mizuno S. Performance of a new hybrid bioartificial liver support system using hepatocytes entrapped within a hydrogel. ASAIO Trans 1989; 35:570-572.

31. Uchino J, Tsuburaya T, Kumagai F, et al. A hybrid bioartificial liver composed of multiplated hepatocyte monolayers. ASAIO Trans 1988; 34:972-977.

32. Uchino J, Matsue H, Takahashi M, et al. A hybrid artificial liver system. Function of cultured monolayer pig hepatocytes in plasma from hepatic failure patients. ASAIO Trans 1991; 37:M337-M338.

33. Koike M, Matsushita M, Taguchi K, Uchino J. Function of culturing monolayer hepatocytes by collagen gel coating and coculture with nonparenchymal cells. Artif Organs 1996; 20:186-192.

34. Taguchi K, Matsushita M, Takahashi M, Uchino J. Development of a bioartificial liver with sandwiched-cultured hepatocytes between two collagen gel layers. Artif Organs 1996; 20:178-185.

35. Nyberg SL, Platt JL, Shirabe K, Payne WD, Hu W-S, Cerra F. Immunoprotection of xenocytes in a hollow fiber bioartificial liver. ASAIO J 1992; 38:M463-467.

36. Tompkins RG, Carter EA. Enzymatic function of alginate immobilized rat hepatocytes. Biotechnol Bioeng 1988; 31:11-18.

37. Dunn JC, Yarmush ML, Koebe HG, Tompkins RG. Hepatocyte function and extracellular matrix geometry: long-term culture in a sandwich configuration. FASEB J 1989; 3:174-177.

38. Enat R, Jefferson DM, Ruiz-Opazo N, Gatmaitan Z, Leinwand LA, Reid LM. Hepatocyte proliferation in vitro: its dependence on the use of serum-free hormonally defined medium and substrata of extracellular matrix. Proc Natl Acad Sci USA 1984; 81:1411-1415.

39. Jauregi HO, McMillan PN, Driscoll J, Naik S. Attachment and longterm survival of adult rat hepatocytes in primary monolayer cultures: comparison of different substrata and tissue culture media formulations. In Vitro Cell Dev Biol 1986; 22:13-22. 
40. Nyberg SL, Shatford RA, Peshwa MV, White JG, Ceraa FB, Hu W-S. Evaluation of a hepatocyte-entrapment hollow fiber bioreactor: a potential bioartificial liver. Biotechnol Bioeng 1993; 41:194-203.

41. Sielaff TD, Hu MY, Amiot B, et al. Gel-entrapment bioartificial liver therapy in galactosamine hepatitis. J Surg Res 1995; 59:179184.

42. Nyberg SL, Mann HJ, Remmel RP, Hu W-S, Cerra FB. Pharmacokinetic analysis verifies $\mathrm{P} 450$ function during in vitro and in vivo application of a bioartificial liver. ASAIO J 1993; 39:M252-M256.

43. Sielaff TD, Nyberg SL, Rollins MD, et al. Characterization of the three-compartment gel-entrapment porcine hepatocyte bioartificial liver. Cell Biol Toxicol 1997; 13:357-364.

44. Sussman NL, Chong MG, Koussayer T, et al. Reversal of fulminant hepatic failure using an extracorporeal liver assist device. Hepatology 1992; 16:60-65.

45. Sussman NL, Gislason GT, Conlin CA, Kelly JH. The Hepatix extracorporeal liver assist device: initial clinical experience. Artif Organs 1994; 18:390-396.

46. Ellis AJ, Hughes RD, Wendon JA, et al. Pilot-controlled trial of the extracorporeal liver assist device in acute liver failure. Hepatology 1996; 24:1446-1451.

47. Nyberg SL, Remmel RP, Mann HJ, Peshwa MV, Hu W, Cerra FB. Primary hepatocytes outperform Hep-G2 cells as the source of biotransformation functions in a bioartificial liver. Ann Surg 1994; 1:5967.

48. Demetriou AA, Whiting J, Levenson SM, et al. New method of hepatocyte transplantation and extracorporeal liver support. Ann Surg 1986; 204:259-271.

49. Giorgio TD, Moscioni AD, Rozga J, Demetriou AA. Mass transfer in a hollow fiber device used as a bioartificial liver. ASAIO Trans 1993; 38:886-892.

50. Rozga J, Williams F, Ro M, et al. Development of a bioartificial liver: properties and function of a hollow fiber module inoculated with liver cells. Hepatology 1993; 17:258-265.

51. Rozga J, Holzman MD, Ro M, et al. Development of a hybrid bioartificial liver. Ann Surg 1993; 217:502-511.

52. Watanabe FD, Mullon CJ, Hewitt WR, et al. Clinical experience with a bioartificial liver in the treatment of severe liver failure. A phase I clinical trial. Ann Surg 1997; 225:484-494.

53. Thomson JA, Itskovitz-Elder J, Shapiro SS, et al. Embryonic stem cell lines derived from human blastocysts. Science 1998; 282:1145-1147.

54. Bernard C. Sur le mechanisme de la formation du sucre dans la foie. CR Acad Sci (Par) 1855; 41:461.

55. Otto JJ, Pender JC, Cleary JH, Sensenig DM, Welch CS. The use of a donor liver in experimental animals with elevated blood ammonia. Surgery 1958; 43:301-309.

56. Eiseman B, Liem DS, Rafucci F. Heterologous liver perfusion in treatment of hepatic failure. Ann Surg 1965; 162:329-345.

57. Watts JM, Douglas MC, Dudley HAF, Gurr FW, Owen JA. Heterologous liver perfusion in acute hepatic failure. Br Med J 1967; 2:341345 .

58. Abouna GM, Kirkley JR, Hull CJ, Ashcroft T, Kerr DNS. Treatment of hepatic coma by extracorporeal pig-liver perfusion. Lancet 1969; I:64-68.

59. Ranek L, Hansen RI, Hilden M, et al. Pig liver perfusion in the treatment of acute hepatic failure. Scand J Gastroenterol 1971(suppl 9):161-169.

60. Pharboo SP, Kennedy J, James IM, et al. Extracorporeal pig-liver perfusion in treatment of hepatic coma due to fulminant hepatitis. Lancet 1971; I:659-665.

61. Tung LC, Haring R, Weber D, Waldschmidt J. Experience in the treatment of hepatic coma by extracorporeal liver perfusion. In: Brunner G, Schmidt FW, eds. Artificial Liver Support. Berlin: SpringerVerlag, 1981:274-279.

62. Chari RS, Collins BH, Magee JC, et al. Brief report: treatment of hepatic failure with ex vivo pig-liver perfusion followed by liver transplantation. N Engl J Med 1994; 331:234-237.
63. Levy MF, Crippin J, Stutton S, et al. Successful transgenic porcine liver perfusion as a bridge to human liver transplantation. Presented at the Transplantation Society XVII World Congress in Montreal, 1998.

64. Filiponi F, Abouna GM, Boggi U, et al. Ex vivo liver perfusion: a successful technique of liver support. Gastroenterology 1998; 114: A1240.

65. Stevens RB, Platt JL. The pathogenesis of hyperacute xenograft rejection. Am J Kidney Dis 1992; 20:414-421.

66. Vaughan HA, Loveland BE, Sandrin MS. GAL-alpha $(1,3)$ GAL is the major xenoepitope expressed on pig endothelial cells recognised by naturally occurring cytotoxic human antibodies. Transplantation 1994; 58:879-828.

67. Soares M, Havaux X, Van Beneden R, et al. Characterisation of rat anti-guinea pig circulating xenoreactive natural antibodies and secreting cells. Transplant Proc 1995; 27:282-285.

68. Galili U, Mandrell RE, Hamahdeh RM, Shohet SB, Griffis JM. Interaction between human natural anti-alpha-galactosyl immunoglobulin $\mathrm{G}$ and bacteria of the human flora. Infect Immun 1988; $56: 1730$.

69. Schaapherder AF, Gooszen HG, te Bulte MT, Daha MR. Human complement activation via the alternative pathway on porcine endothelium initiated by IgA antibodies. Transplantation 1995; 60:287291.

70. Parker W, Bruno D, Holzknecht ZE, Platt JL. Characterization and affinity isolation of xenoreactive human natural antibodies. J Immunol 1994; 153:3791-3803.

71. Schraa EO, Stockmann HBAC, Scheringa M, Broekhuizen AJ, Marquet RL, Ijzermans JNM. IgG, but not IgM, mediates hyperacute rejection in hepatic xenografting. Xenotransplantation 1998; 6:110116.

72. Ellison RT, Horsburgh RC, Curd J. Complement levels in patients with hepatic dysfunction. Dig Dis Sci 1990; 35:231-235.

73. Grinyo JM, Cruzado JM, Riera M, et al. Functional and pathologic outcome after complement inactivation in a pig kidney-human blood xenoperfusion model. Transplant Proc 1997; 29:2318-2321.

74. Schön MR, Lemmens HP, Neuhaus P, et al. Improved xenogeneic extracorporeal liver perfusion. Transplant Proc 1994; 26:12931297.

75. Tuso PJ, Cramer DV, Yasunaga C, Cosenza CA, Wu GD, Makowka L. Removal of natural human xenoantibodies to pig vascular endothelium by perfusion of blood through pig kidneys and livers. Transplantation 1993; 55:1375-1378.

76. Tector AJ, Elias N, Rosenberg L, et al. Mechanisms of resistance to injury in pig livers perfused with blood from patients in liver failure. Transplant Proc 1997; 29:966-969.

77. Collins BH, Chari RS, Magee JC, et al. Mechanisms of injury in porcine livers perfused with blood of patients with fulminant hepatic failure. Transplantation 1994; 58:1162-1171.

78. Cotterell AH, Collins BH, Parker W, Harland RC, Platt JL. The humoral immune response in humans following cross-perfusion of porcine organs. Transplantation 1995; 60:861-868.

79. McKenzie IFC, Osman N, Cohney S, Sandrin MS. Strategies to overcome hyperacute rejection of pig-to-human xenografts. Transplant Proc 1997; 29:973-974.

80. Pöhlein C, Pascher A, Baumann P, et al. Transgenic porcine livers reduce liberation of humoral mediators during xenoperfusion with human blood. Transplant Proc 1996; 28:772-774.

81. Yagi T, Satoh S, Kanazawa A, et al. Extracorporeal xenoperfusion of the pig liver as a liver assist device: effects of prostaglandin E1 and soluble complement receptor type 1. Transplant Proc 1998; 30:74-75.

82. Pascher A, Pöhlein C, Stangl M, et al. Application of immunoapheresis for delaying hyperacute rejection during isolated xenogeneic pig liver perfusion. Transplantation 1997; 63:867-875. 
83. Abouna GM, Serrou B, Boehmig HG, Amemiya H, Martineau G. Long-term hepatic support by intermittent multi-species liver perfusions. Lancet 1970; I:391-396.

84. Te Velde AA, Flendrig LM, Ladiges NC, Chamuleau RA. Immunological consequences of the use of xenogeneic hepatocytes in a bioartificial liver for acute liver failure. Int J Artif Organs 1997; 20:229-233.

85. Gerlach J, Jorres A, Trost O, et al. Side effects of hybrid liver support therapy: TNF-alpha liberation in pigs, associated with extracorporeal bioreactors. Int J Artif Organs 1993; 16:604-608.

86. Baquerizo A, Mhoyan A, Shirwan $\mathrm{H}$, et al. Xenoantibody response of patients with severe acute liver failure exposed to porcine antigens following treatment with a bioartificial liver. Transplant Proc 1997; 29:964-965.
87. Triulzi DJ, Jochum EA, Marino IR, Strazl TE. Heteroagglutinins and their significance in baboon hepatic xenotransplantation. Transplantation 1995; 60:127-131.

88. Patience C, Takeuchi Y, Weiss RA. Infection of human cells by an endogenous retrovirus of pigs. Nat Med 1997; 3:282-286.

89. Martin U, Steinhoff G, Kiessig V, et al. Porcine endogenous retrovirus (PERV) was not transmitted from transplanted porcine endothelial cells to baboons in vivo. Transplant Int 1998; 11:247-251.

90. Heneine W, Tibell A, Switzer B, et al. Absence of evidence of infection with the porcine endogenous retrovirus (PERV) in human recipients of pig islet cells. Transplantation Society XVII World Congress, Montreal, 1998. 